\title{
EDITORIAL
}

\section{STATUS OF ORTHODONTIC SERVICES IN KENYA}

Orthodontics is one of the disciplines for specialisation in Dentistry. It concerns the diagnosis, prevention and treatment of dental and certain facial irregularities that lead to malpositioning of teeth. The scientific term for these problems is malocclusion, which in lay terms means crooked or irregular teeth.

The average treatment period necessary to treat malocclusion is 24 months. In a few instances, the treatment may be shorter (9-15 months), or it may be longer ( $>3$ years). The duration of treatment will vary depending on the complexity of the problem, the type of treatment technique used, the experience of the doctor (Orthodontist) and the cooperation of the patient. Occasionally, a combination of orthodontics and surgery is necessary to position the teeth and jaws in correct alignment. Both children and adults can undergo the treatment.

A few recent studies on the prevalence of malocclusion have been conducted in Nairobi amongst 3-6, $(1,2)$ and 13-15 year-olds $(3,4)$. Amongst the 1315 year-olds, it has been shown that about $72 \%$ of the children have some form of malocclusion. However, the subjective and objective needs of treatment were found in $33 \%$ and $29 \%$ of the subjects respectively. The majority of children were judged to require fixed orthodontic appliances compared to removable appliances to correct the malocclusions satisfactorily.

Fixed appliance therapy is superior to removable appliance therapy in terms of the results of treatment. To a very large extent, the proper use of fixed appliances demands specialty training. Indeed, in unskilled hands, these appliances can produce a very unsatisfactory outcome and, in some situations can cause serious harm to the teeth and facial harmony. Poor treatment outcome has a time and financial implication for the patient, and a loss of esteem and trust for the profession. Fixed appliance therapy is undertaken mainly in private practice and only to a very limited extent in two public institutions in Kenya (University of Nairobi Dental School and Kenyatta National hospital).

To the author's knowledge, there are nine Kenyan orthodontists world-wide. Six of these practice in the United States of America, two are in full-time private practice in Kenya and one teaches at the University of Nairobi Dental School. This gives a ratio of one orthodontist to ten million Kenyans compared to one orthodontist to twenty one thousand Americans(5). Currently therefore, the treatment of all types of malocclusions, even the complex ones, remains largely in the hands of the general dental practitioner and the few paediatric dental specialists in the country. There are no postgraduate programmes offering orthodontic training in Kenya and at the moment there are three dentists pursuing the specialty outside the country. This rather pathetic situation is currently the best in the East African region!

As is the case elsewhere in the world, orthodontic treatment is normally expensive due to the long treatment periods involved. Whereas the treatment is covered either wholly or partially by third parties in most countries, extremely few corporations or insurance companies in Kenya undertake to pay for this treatment. The general view is that orthodontic treatment is undertaken for cosmetic reasons only. However, development of low self-esteem because of having dental and facial aesthetics below the norm as perceived by self and public is a handicap that can lead to psychosocial problems, particularly in children. Orthodontic treatment is frequently undertaken to correct existing and/or to prevent future dental ill health where a malocclusion would be the cause of the problem. It is also undertaken in specific situations to improve function such as mastication, phonation, respiration and deglutition. Furthermore, the orthodontist will often be called upon to constitute an interdisciplinary team in other disciplines such as Prosthodontics, Restorative dentistry, oral-maxillofacial surgery, Periodontics and Paedodontics. By helping to align teeth in the desired positions, other members of the team can accomplish their tasks to a higher standard. In modern living, orthodontic treatment is a health issue, and the demand for improved aesthetics should not be viewed as vanity. Patients judged objectively to be in need of orthodontic treatment and have a dental treatment scheme should be assisted financially to access orthodontic services.

Patients who would benefit from this treatment abound in our society. Most of them would benefit from specialist attention with fixed appliances. Indeed, it is disheartening to note that a large proportion of patients with complex malocclusions related to severe inter-arch discrepancies, cleft-lip and palate and deviations due to syndromes in the facial regions have no access to an orthodontist.

It has been argued that where there is limited orthodontic manpower, the demand for treatment may be met by a supervised general practitioner-based service which could then produce treatment for a higher population(6). On the other hand, studies have shown that where orthodontic treatment is mainly done by general dental practitioners and performed with removable appliances, the outcome is often of a suboptimal standard(7,8). As expected therefore, in some of the treatment results the patients are dissatisfied(9). This outcome is frequently encountered clinically among Kenyans.

It is therefore important to impress upon the dental practitioners the necessity for careful selection of the 
malocclusions that can be reasonably managed by a specific appliance systems putting into consideration the competency and experience of the practitioner(10). Continuing education to improve ones skills for the benefit of patients is crucial(5).

In order to provide advice on orthodontic treatment on the basis of scientific knowledge, information about societal norms (the range of deviations in occlusion accepted by society) is necessary $(6,11)$. This is because degrees of acceptance of own occlusal disfigurement may be influenced by the sociolcultural norms(11). No information on normative standards for dentofacial aesthetics has been documented for Kenyans so far, and many patients are treated with the goal of achieving European and American aesthetic standards. This is an area of research that needs to be addressed.

In conclusion, financial constraints and shortage of orthodontists remain the greatest hinderances to the proper management of the majority of Kenyans needing specialist orthodontic services.

Dr. P.M. Ng'ang'a BDS, MSD, Ph.D. Specialist Orthodontist/Senior Lecturer, Department of Dentistry and Orthodontics, Faculty of Dental Sciences, University of Nairobi, P.O. Box 19676 Nairobi, Kenya.

\section{REFERENCES}

1. Kabue, M. M., Moracha, J. and Ng'ang'a, P.M. Malocclusion in children aged 3-6 years in Nairobi, Kenya. East Afr. Med. J. 1995; 72:210-212.
2. Ngatia, E. M., Ng'ang'a, P.M., Imungi, J.K., Muita, J.W. and Ogaard, B. Artificial sucking habits and malocclusion in 3-5 year-olds in Nairobi. Afr. J. Oral. Hlth. Sci. 2001; 2:27-29.

3. Ng'ang'a, P. M., Ohito, F. B., Ogaard, B. and Valderhaug, J. The prevalence of malocclusion in 13-15 year-old children in Nairobi, Kenya. Acta. Odontol Scand. 1996; 54:126-130.

4. Ng'ang'a, P. M., Stenvik, A., Ohito, F. and Ogaard, B. The need for orthodontic treatment in 13-15 year-olds in Nairobi, Kenya. Acta. Odontol Scand. 1997; 55:325328.

5. Christensen G. J. What is the role of specialties in Dentistry? JADA. 2003; 134:1517-1519.

6. Espeland, L. V., Ivarsson, K. and Slenvik, A. New Norwigian Index of Orthodontic treatment related to Orthodontic concern among 11 year olds and their parents. Community Dent. Ora. Epidemiol. 1992; 20:274279.

7. Burgersdijk, R. C. W., Truin, G. J., Frankenmolem, F. W. A., Kalsbeek, H., Van't Hof, M. A. and Mulder, J. Malocclusion and orthodontic treatment need of 1574 year-old Dutch adults. Community Dent Oral Epidemiol. 1991; 19:64-67.

8. Salonen, L., Mohlin, B., Gozlinger, B. and Hellden, I. Need and demand for orthodontic treatment in an adult Swedish population. Eur. J. Orthod. 1992; 14:359-368.

9. Gravely, J. F. Who should practice orthodontics? Brit. J. Orthod. 1989; 16:235-241.

10. Ng'ang'a, P. M. The need for an Orthodontic Service in Kenya. KDA News Issue no. 2 Sept. 2001:6-7.

11. Espeland, L. V. and Stenvik, A. Perception of personal dental appearance in young adults: Relationship between occlusion, awareness and satisfaction. Am. J. Orthod. Dentofac. Orthop. 1991; 100:234-241. 